\title{
CONSIDERAÇÕES SOBRE O PROCESSO DE GESTÃO E CONTROLE \\ DE ESTOQUE DE MERENDA ESCOLAR REALIZADO EM UMA \\ INSTITUIÇÃO DE ENSINO DA CIDADE DE SÃO PAULO
}

\author{
CONSIDERATIONS ABOUT THE SCHOOL SNACK MANAGEMENT \\ AND CONTROL PROCESS HELD IN A EDUCATIONAL INSTITUTION \\ IN THE CITY OF SÃO PAULO
}

\author{
Recebimento: 19/08/2019 - Aceite: 06/01/2020 - Publicação: 28/02/2020 \\ Processo de Avaliação: Double Blind Review \\ Luiz Claudio Gonçalves ${ }^{1}$ \\ Doutor em Engenharia de Produção da Universidade Metodista de Piracicaba (UNIMEP) \\ Professor da Faculdade de Tecnologia da Zona Sul de São Paulo (FATECSul) \\ luizgoncalves@uol.com.br \\ Gabriela dos Santos \\ Faculdade de Tecnologia da Zona Sul de São Paulo (FATECSul) \\ gabilule@yahoo.com.br \\ Valter Paulo de Lima \\ Faculdade de Tecnologia da Zona Sul de São Paulo (FATECSul) \\ vvalterpaulo@gmail.com
}

\section{RESUMO}

Um estoque bem gerido e organizado evita altos custos de manutenção e de falta de produtos. Com base nesses argumentos, esta investigação busca identificar quais são as atividades executadas no processo de gestão e controle de estoque de merenda escolar e, também, quais são as vantagens e desvantagens trazidas por ele para uma instituição de ensino situada na cidade de São Paulo. Como resultados obtidos na pesquisa, observa-se que a instituição faz uso de algumas técnicas e ferramentas descritas na pesquisa, visando auxiliam na melhoria do processo, diminuindo assim, o índice de faltas de produtos. Verificou-se também que, após a implantação do sistema informatizado SAESP, a instituição consegue maior e melhor

\footnotetext{
${ }^{1}$ Autor para correspondência: Faculdade de Tecnologia da Zona Sul de São Paulo (FATECSul): Rua Frederico Grotte, 322 - Jardim São Luís, São Paulo - SP, 05818-270- Brasil.
} 
autonomia para gerenciar o seu cardápio. No atual cenário competitivo, definir métodos efetivos de gestão e controle de estoque torna-se um grande diferencial para que as empresas possam ser competitivas e assim obterem o devido reconhecimento do mercado. Nesse cenário, tanto o gestor quanto sua equipe devem procurar reduzir custos, otimizar tempo e espaço, evitar desperdícios, executar a identificação e disposição adequada de produtos e controlar a sua rotatividade.

Palavras-chave: Controle de Estoque; Gestão de Estoque; Melhoria de Processo.

\begin{abstract}
A well-managed and organized inventory avoids high maintenance costs and product shortages. Based on these arguments, this investigation seeks to identify what activities are carried out in the process of management and control of school meals and also what are the advantages and disadvantages brought by the same, for an educational institution located in the city of São Paulo. As results obtained in the research, it is observed that the institution makes use of some techniques and tools described in the research, aiming to help in the improvement of the process, thus reducing the rate of product shortages. It was also found that, after the implementation of the SAESP computerized system, the institution achieves greater and better autonomy to manage its menu. In the current competitive scenario, defining effective inventory management and control methods becomes a major differential for companies to be competitive and thus obtain due market recognition. In this scenario, both the manager and his team must try to reduce costs, optimize time and space, avoid waste, perform the proper identification and disposal of products and control their turnover.
\end{abstract}

Keywords: Inventory Control; Inventory Management; Processes improvement.

\title{
1. INTRODUÇÃO
}

Segundo Oliveira (1997) e Abreu (2019) a merenda escolar representa um importante atrativo que possibilita a manutenção da frequência em instituições de ensino público. Tal situação deve-se ao fato, de que muitos alunos das escolas públicas brasileiras tem a merenda escolar, como a sua única refeição diária (FNDE, 2019).

Visando a melhoria do processo de gestão e controle de estoques dos insumos utilizados na elaboração das merendas oferecidas por todas as instituições de ensino, o Governo Estadual de São Paulo implantou o Sistema de Alimentação do Estado de São Paulo (SAESP), sistema esse que veio substituir o antigo processo manual de controle de estoque, o qual era

Revista ENIAC Pesquisa, Guarulhos (SP), V.9, n.1, fev.- jul. 2020. 
realizado, por meio do envio quinzenais de ofícios para as diretorias regionais de ensino do estado. (SÃO PAULO, 2019).

Dessa forma, com base nos argumentos contidos nos parágrafos anteriores, o presente artigo tem a finalidade de descrever quais são as fases do processo de gestão e controle de estoques executados em uma instituição de ensino na cidade de São Paulo, visando identificar quais são as vantagens e desvantagens trazidas pela implantação desse processo. .

É importante também mencionar que, a realização desta investigação tem como justificativa, o fato de que existem inúmeras escolas na cidade de São Paulo, as quais, diariamente necessitam gerir e controlar os seus estoques de insumos visando fornecer uma alimentação sadia para seus alunos. Além disso, a pesquisa, também, se justifica pelo fato de que, conforme Carretoni (2000), o alto valor investido, a necessidade de dimensionar estoques adequados, as prevenções para evitar faltas ou estoques excedentes e a garantia da qualidade e integridade dos insumos tendem a se tornar fatores essenciais para que as instituições possam atender as necessidades de seus clientes, os quais, nessa investigação, trata-se da correta alimentação dos alunos.

\section{REFERENCIAL TEÓRICO}

Para um melhor entendimento a respeito da importância do processo de gestão e controle de estoques aplicado à correta manutenção dos insumos necessários para a preparação da merenda escolar nas escolas, é importante a apresentação de alguns conceitos, a seguir:

\subsection{ESTOQUE}

Viana (2012) destaca que estoque trata da acumulação de recursos em um sistema de transformação sendo capaz de prever demanda, garantindo melhor abastecimento e proporcionando assim uma grande economia. Ele ressalta ainda que "estoques são recursos ociosos que possuem valor econômico, os quais representam um investimento destinado a incrementar as atividades de produção e servir aos clientes". (VIANA, 2012, p.144) 
Estoque é todo aquele material que de forma improdutiva fica armazenado por um determinado período, ficando disponível para ser utilizado no processo produtivo., sendo esses importantes por causa da sua finalidade (industrial, comercial e de serviços) em manter um nível mínimo para se iniciar a operação da empresa (PAOLESCHI, 2018).

Segundo Martins e Alt (2011, p.68) “estoque é o acúmulo armazenado de recursos materiais em um sistema de produção e/ou operações".

Já de acordo com Ballou (2006) estoque são todos os produtos acumulados desde a matéria-prima até o produto acabado, podendo esses surgir em qualquer parte do processo, sendo armazenados em pequenos ou grandes volumes, de acordo com a necessidade de cada empresa.

Na visão de Viana (2012) quando se menciona avalia a importância do estoque para a operação empresarial, deve-se levar em conta o custo relacionado aos investimentos e de suas manutenções. Portanto, deve-se obter um nível adequado para que as atividades não sejam interrompidas, por falta de material, tendo como principais funções o atendimento do consumo imediato, evitando assim que a sua linha de produção seja interrompida por falta de produtos.

Já Ching (2010) salienta que o principal impacto do estoque na operação empresarial está diretamente relacionado aos custos, pois quanto maior a quantidade de itens estocados e maior volume dos mesmos, maior será o custo de manutenção do estoque, quanto maior for o pedido solicitado maior será o nível médio do estoque, o que acarreta um maior valor do custo de manutenção, no entanto quanto maior for a compra, menor será a quantidade de pedidos solicitados, o que gera um menor custo na reposição do estoque. Para tal, faz-se necessário encontrar o ponto de equilibro entre aquisição e a estocagem, evitando assim custos desnecessários, por falta ou alto volume de estoque.

Conforme Martins e Alt (2011) os estoques constituem parcela importante dos ativos de qualquer empresa; por essa razão, recebem um tratamento contábil minucioso. Para esses autores, para efeitos legais os estoques são classificados em três principais categorias:

- Estoque de peças/materiais: classificam nesse grupo, peças/ materiais que a empresa adquiriu e armazenou para utilizar no processo produtivo. 
- Estoque de produto em processo: pertencem a esse grupo, todos os itens que já entraram no processo produtivo, e estão sendo transformados, porém ainda não estão acabados.

- Estoque de produto acabado: incorporam neste grupo os produtos já finalizados e que estão prontos para venda.

\subsection{GESTÃO DE ESTOQUE}

Segundo Martins e Alt (2011) a gestão de estoques se caracteriza por auxiliar os gestores na tomada de decisões referente à produtividade e utilização dos estoques, sendo de grande importância quando bem administrada, apresentando informações que visam explicitar o que manter no estoque, quanto reabastecê-lo e quando requisitá-lo.

Já Ballou (2006), ressalta que o processo de gestão de estoque é de extrema importância, pois é parte de um processo que é responsável por executar várias atividades que buscam atender as necessitadas da empresa, visando à redução de custos, por meio do giro do capital investido em materiais. Para esse autor, esse processo engloba inúmeras dificuldades, uma vez que para se obter os melhores resultados é necessário a utilização de várias técnicas.

Em qualquer empresa, a preocupação da gestão de estoques está em manter o equilíbrio entre diversas atividades, como custo de aquisição, custo de estocagem e distribuição, níveis de atendimento das necessidades dos usuários etc. Buscando, de tal maneira que as necessidades efetivas dos consumidores estejam atendidas com o menor custo e risco de faltas possíveis. Assegurando a seus consumidores o efetivo fornecimento e que o valor obtido pela continuidade de fornecimento seja inferior ao da falta. (VIANA, 2012)

\subsection{CONTROLE DE ESTOQUE}

Segundo Dias (2010), o estoque é de extrema importância para as empresas, pois, por meio do controle e acompanhamento dos níveis de estoque e controle dos investimentos financeiros as empresas podem atender sua linha de produção ou vendas de produtos, o estoque pode ser definido como: matéria-prima, produtos em processos e produtos acabados. 
Já para Viana (2012) o controle de estoque é um processo pelo qual se registra, fiscaliza e acompanha a entrada e saída de mercadorias, podendo ser utilizado independente do ramo da empresa, seja ela indústria, comércio ou serviços. Com a atual tecnologia existente, esse procedimento se tornou mais prático facilitando assim, o manuseio e compreensão de quais itens estão inseridos no estoque, podendo-se então controlar as divergências, obsolescências, perdas do estoque.

Ainda de acordo com Dias (2010) o processo de controle de estoque deve ser definido conforme o perfil de cada empresa, esses estudos começaram nos tempos antigos onde as empresas definiam qual o tipo de sistema a ser utilizado por meio de duas perguntas básicas: Quanto? Quando? Com isso foram criadas as teorias de Lote Econômico de Compras (LEC) e Lote Econômico de Fabricação (LEF) para atender a essas necessidades. Para esse autor, os objetivos principais do controle de estoque são:

- Determinar o nível do estoque mínimo.

- Determinar o período de renovação do estoque.

- Determinar a quantidade de estoque necessário para atender um determinado período.

- Relatar os pedidos desde aquisição de material ao setor de compras.

- Receber, conferir e armazenar os materiais atendendo as suas necessidades específicas.

- Controlar, por meio de relatórios os níveis de estoque em relação a quantidade e valores.

- Avaliar o estoque por meio dos inventários periódicos.

- Identificar e retirar do estoque os produtos obsoletos e danificados.

\subsection{TÉCNICAS E FERRAMENTAS APLICADAS AO CONTROLE DE ESTOQUE}

\subsubsection{Classificação da Curva $\mathrm{ABC}$}

Para Pozo (2016), o princípio da classificação ABC foi criado por Pareto, o qual em 1897 realizou um estudo, na Itália sobre a distribuição de renda. Por meio desse estudo, pode 
perceber que a distribuição de riqueza não era uniforme, ocorrendo uma grande concentração de riqueza (80\%) nas mãos de uma pequena parcela da população (20\%).

De acordo Bertaglia (2009) e Carvalho (2016) classificação ABC é uma técnica de uso do gestor de estoques, a qual permite a identificação da quantidade de itens do estoque que exercem maior impacto econômico no valor total do estoque. Esses itens são classificados como:

- Classe A: Grupo de itens mais relevantes, devendo ter uma atenção, podendo ser itens do estoque com uma demanda de $60 \%$ em um determinado período.

- Classe B: Grupos de itens que é classificado como intermediário, em termos de importância, podendo apresentar uma demanda de 30\%, em determinado período.

- Classe C: Grupos de itens com menor relevância e, conseguintemente menor atenção, tendo uma demanda de até $10 \%$ dentro de determinado período

\subsubsection{Classificação XYZ (Análise de Criticidade)}

De acordo com Gasnier (2007) a classificação XYZ, também chamada de Análise de Criticidade organiza os itens com base no critério do impacto, resultante da falta de material nos processos internos da organização, agregando mais informações para a rotina de planejamento, reposição e gerenciamento.

Segundo Maehler, Ceretta e Cassanego Junior (2004), a classificação XYZ ou Análise da Criticidade, origina-se da gestão da qualidade, a qual decorre de uma avaliação do impacto que determinados itens geram na operação de uma empresa, ou seja, na parada de funcionamento da empresa. Nas farmácias, essa classificação decorre por meio da facilidade de obtenção ou substituição de algum item por outro e, também, na velocidade de obsolescência. De acordo com Viana (2012), classifica os itens de estoque de três maneiras:

- Classe X: São itens cuja ausência é de suma importância, causando total paralisação nas operações essenciais, colocando em risco o patrimônio.

- Classe Y: São itens de média criticidade, ou seja, podem ser substituídos por produtos semelhantes, porém são vitais para a empresa. 
- Classe Z: São itens de baixa criticidade, não acarretam paradas nas operações da empresa e assim, não trazem prejuízo para a empresa.

Gasnier (2007) salienta que a Análise de Criticidade pode e deve ser usada em conjunto com a classificação $\mathrm{ABC}$ visando dar uma maior e melhor confiabilidade para o processo de controle de estoques.

\subsubsection{Inventário}

Martins e Alt (2011) destacam que o inventário físico é uma ferramenta comum na gestão de estoque que consiste na contagem física dos itens estocados onde as informações obtidas são confrontadas com os registros do controle de estoque de modo que se obtenha um indicador de produtividade.

Sob a ótica de Arnold (2011) inventário é a ferramenta que é responsável pela contagem física de todos os itens existentes no estoque. Já para Castiglioni (2010) inventário refere-se a contagem de todos os itens presentes no estoque, para que haja comparação com o contábil, pois o estoque precisa ser mensurado no balanço da empresa e futuras auditorias onde ocorreram análises das práticas adotadas. Esse mesmo autor destaca ainda que, o inventário traz um grande benefício, na medida em que é possível verificar os desvios ocorridos no controle de estoque, como por exemplo, falhas no apontamento de itens inexistentes.

\subsubsection{Giro de Estoque}

Para Dias (2010) o giro de estoque calcula quantas vezes, por unidade de tempo, o estoque se renovou. $\mathrm{O}$ giro de estoque pode ser calculado por:

Giro de estoque $=$ Vendas Anuais (unidades)/Estoque Médio (unidades)

\subsection{A IMPORTÂNCIA DO SISTEMA DA INFORMAÇÃO PARA A GESTÃO E CONTROLE DE ESTOQUES}

Revista ENIAC Pesquisa, Guarulhos (SP), V.9, n.1, fev.- jul. 2020. 
Na concepção de Martins e Alt (2011) com o controle de estoque informatizado é possível se analisar as vendas do mês, fazendo comparações com outros períodos, além de se saber quando será necessário fazer novos pedidos, uma vez que o estoque atinge o nível mínimo estipulado, além de se ganhar velocidade nas operações.

Segundo Viana (2012, p.408) “Os benefícios gerados pela informatização motivaram as consultorias do ramo a desenvolverem e oferecerem uma série de softwares de gerenciamento de estoques, plenamente exequíveis e adaptáveis às empresas de pequeno e médio porte".

\section{METODOLOGIA}

Com base nos argumentos contidos nos parágrafos anteriores, a presente investigação busca elucidar o seguinte problema de pesquisa: Quais são as vantagens e desvantagens trazidas pela implantação de um efetivo processo de gestão e controle de estoques das merendas escolares, para uma instituição de ensino situada na cidade de São Paulo?

A partir do problema de pesquisa anteriormente apresentado, a investigação tem como principal objetivo descrever quais são as fases do processo de gestão e controle de estoque executado em uma instituição de ensino ( escola estadual) localizada no bairro de Paraisópolis na cidade de São Paulo, cuja clientela é formada, quase exclusivamente, por crianças que moram no próprio bairro e em bairros do entorno. Ela possui cerca de 60 funcionários e atende diariamente, aproximadamente 600 alunos servindo cerca de 700 refeições por dia.

Sendo assim, tendo em vista o objetivo geral aqui descrito, os objetivos específicos da investigação são: descrever como é realizado o processo de gestão e controle de estoque na instituição investigada, bem como identificar quais são as principais vantagens e desvantagens existentes na implantação do referido processo.

Cabe salientar que, para se alcançar os objetivos aqui expostos, a investigação está embasada em uma pesquisa qualitativa, descritiva e bibliográfica, apoiada em um estudo de caso realizado em uma instituição de ensino, situada na cidade de São Paulo. Já a coleta de dados, utilizada na investigação foi apoiada em uma rigorosa análise crítica da literatura pertinente ao tema. Para trazer maior confiabilidade à coleta de dados foi realizado uma visita técnica às instalações da instituição de ensino investigada, onde foram feitas observações

Revista ENIAC Pesquisa, Guarulhos (SP), V.9, n.1, fev.- jul. 2020. 
pessoais no processo de gestão e controle de estoque, aliado à realização de uma entrevista com a diretora de ensino da referida instituição.

\section{RESULTADOS}

\subsection{DESCRIÇÃO DA EMPRESA INVESTIGADA}

A instituição objeto desta investigação trata-se de uma escola estadual localizada no bairro de Paraisópolis na cidade de São Paulo, cuja clientela é formada, quase exclusivamente, por crianças que moram no próprio bairro e em bairros do entorno. Ela possui cerca de 60 funcionários e atende diariamente, aproximadamente 600 alunos servindo cerca de 700 refeições por dia.

\subsection{ANÁLISE DOS DADOS COLETADOS NA PESQUISA}

A partir dos obtidos pelas observações pessoais ocorridas na visita técnica às instalações da instituição de ensino, bem como pela entrevista realizada com a Diretoria de Ensino da mesma, foi possível identificar que a escola faz uso de um processo de gestão e controle de estoque, o qual faz uso de um sistema informatizado denominado de SAESP e, também por uma planilha eletrônica desenvolvida pela responsável do setor de merenda da instituição, onde são efetuados o cadastro de todos os produtos que chegam e saem do estoque, a conferência do estoque, baixa diária de consumo, recebimento de produtos (para elaboração da merenda), a sanitização dos ambientes2, o cadastro de dietas especiais, a troca e o remanejamento de produtos.

Também foi observado, o uso de algumas técnicas relacionadas com o controle de estoque, tais como, a realização de inventário, bem como, o uso da análise da curva $\mathrm{ABC}$ e $\mathrm{XYZ}$, as quais auxiliam na tomada de decisões referente ao impacto econômico e falta de alguns itens do estoque.

\footnotetext{
${ }^{2}$ Sanitização de Ambientes. É um processo de higienização e eliminação de agentes causadores de infecções, alergias, patógenos que causam bronquite, asma, renite dentre outros desconfortos provenientes de fungos, mofos.
} 


\subsection{ANÁLISE DO PERFIL DO ESTOQUE INVESTIGADO}

O estoque está localizado em uma sala situada na lateral da escola e esse é dividido em: Estoque seco e enlatados e estoque de perecíveis. Cabe destacar que os itens de estoque são armazenados em prateleiras aptas a suportarem carga máxima de $250 \mathrm{kgf}$.

\subsection{TÉCNICAS E FERRAMENTAS UTILIZADAS NO PROCESSO DE GESTÃO E CONTROLE DE ESTOQUE}

Uma técnica apontada pela instituição para controlar o seu estoque e, assim melhor atender as suas demandas é a realização da análise da curva $\mathrm{ABC}$ aplicada à compra de produtos para atender ao cardápio. Dessa forma, na classe "A" estão os produtos que não podem faltar no preparo diário das refeições, tais como, óleo, alho e gás. Na classe "B" estão a cebola, cheiro verde e pimentão. E por fim, na classe "C" aparece o leite, ovos e congelados. A realização dessa análise proporciona uma melhor programação de compras por se tratar de alimentos perecíveis. Aliada a aplicação da curva $\mathrm{ABC}$ também é utilizada a análise XYZ visando avaliar quais itens são imprescindíveis para a elaboração da merenda diária.

Também foi evidenciado que a instituição faz uso do inventário de estoque, o qual é executado mensalmente, desde janeiro até novembro. Dessa forma, por meio desse inventário o Departamento de Alimentação e Assistência ao Aluno (DAAA), identifica quais são os itens que estão em falta no estoque, visando assim efetuar a reposição desses no próximo ciclo de entrega.

\subsection{APLICAÇÃO DO SISTEMA DE ALIMENTAÇÃO DO ESTADO DE SÃO PAULO (SAESP) NA GESTÃO E O CONTROLE DE ESTOQUE DA INSTITUIÇÃO DE ENSINO}


A Fundação Nacional Desenvolvimento da Educação (FNDE, 2019) do Ministério da Educação desenvolveu em 1955, o Programa Nacional de Alimentação Escolar (PNAE, 2019), considerado o maior programa de alimentação escolar do mundo, por oferecer aos alunos da rede pública de educação uma merenda de qualidade, porque, em seu entendimento, a oferta de refeições diárias contribuirá para o crescimento e o desenvolvimento biopsicossocial, aprendizagem e reduzirá a evasão e repetência dos alunos. Também conhecido como "Merenda Escolar", essa iniciativa tem como principal finalidade possibilitar aos alunos beneficiários uma melhoria na oferta de refeições diárias, reduzindo a evasão e repetência.

Para tal, o FNDE repassa a estados, municípios e escolas federais, valores financeiros de caráter suplementar efetuados em 10 parcelas mensais (de fevereiro a novembro) para a cobertura de 200 dias letivos, conforme o número de matriculados em cada rede de ensino.

Com a finalidade de atender ao Programa Nacional de Alimentação Escolar a Secretaria da Educação do Estado de São Paulo criou em 2015, o Sistema de Alimentação do Estado de São Paulo (SAESP), o qual tem como principal objetivo, aprimorar a gestão do Programa Nacional de Alimentação Escolar (PNAE), pois substitui e digitaliza as informações que habitualmente eram enviadas por ofícios e/ou e-mails (trocas, inutilizações, dietas especiais, remanejamentos, sanitização, recebimentos de boletos, entre outros), possibilitando assim, um retorno mais rápido das ocorrências e melhor monitoramento das informações.

Com a aplicação do SAESP, o controle do estoque das instituições de ensino passou a ser executado por meio de baixas diárias, identificando a quantidade de produtos retirados e número de alunos comensais efetivamente atendidas pelo PNAE.

\subsection{VANTAGENS E DESVANTAGENS DO PROCESSO}

Na opinião da diretora da instituição de ensino investigada, a implantação do SAESP, aliado a aplicação de algumas técnicas descritas anteriormente, trouxe diversas vantagens para o processo de controle de estoque da instituição, tais como:

- Otimização de todo o processo - com a aplicação das técnicas de controle de estoque aliado à implantação do SAESP foi possível à otimização de todo o processo, haja vista que agora há uma utilização mais racional dos produtos utilizados na

Revista ENIAC Pesquisa, Guarulhos (SP), V.9, n.1, fev.- jul. 2020. 
elaboração da merenda. Além disso, foi percebido, um aumento na assertividade das informações, acarretando uma melhor confiabilidade para todo o processo.

- Redução no índice de faltas - com o uso das análises ABC e XYZ foi possível melhor avaliar quais produtos efetivamente não devem faltar no estoque.

- Melhoria na previsão e rapidez de abastecimento - por meio da realização de inventários mensais, há uma maior precisão e garantia de abastecimento, pois assim, é possível, facilmente se identificar quais são os itens que estão em falta, visando o mais rápido possível efetuar a reposição desses no próximo ciclo de entrega.

Todavia, além das vantagens acima citadas, também foram detectadas algumas barreiras ao processo, tais como:

- Necessidade de alguns ajustes operacionais no SAESP - Após o lançamento da baixa diária no sistema, não é mais possível acrescentar algum outro item que seja necessário.

\section{CONSIDERAÇÕES FINAIS}

Essa investigação teve como objetivo identificar quais as fases existentes, bem como quais foram as vantagens e desvantagens geradas pela aplicação de um processo de gestão e controle de estoque de merendas executado em uma instituição de ensino, a qual atende aproximadamente 600 alunos diariamente na cidade de São Paulo. Dessa forma, durante a pesquisa, verificou-se que após a implantação do sistema informatizado SAESP aplicado ao processo de gestão e controle de estoque, a instituição de ensino obteve maior e melhor autonomia para gerenciar o seu cardápio, facilitou a inserção dos boletos recebidos, o cadastro de dietas especiais e o inventário mensal do seu estoque.

As evidências aqui obtidas ressaltam que se faz necessário o uso de algumas técnicas e ferramentas descritas, uma vez que essas auxiliam na otimização do processo, diminuindo assim, o índice de faltas de produtos. O uso do sistema SAESP traz ainda informações precisas

Revista ENIAC Pesquisa, Guarulhos (SP), V.9, n.1, fev.- jul. 2020. 
e cruciais para a efetividade de todo o processo, como a correta definição do momento de ressuprimento e do controle de perdas de materiais.

Por fim, os resultados na investigação tendem a proporcionar a todos os envolvidos, a necessidade de se desenvolver uma visão mais abrangente, acerca de todo o processo de gestão e controle de estoque da merenda escolar, Além disso, propiciou também um melhor entendimento do funcionamento e importância do sistema informatizado SAESP, bem como da real relevância em se estabelecer um efetivo processo de gestão e controle de estoque dos itens necessários à elaboração da merenda escolar.

\section{REFERÊNCIAS}

ABREU, M.: Alimentação escolar: combate à desnutrição e ao fracasso escolar ou direito da criança e ato pedagógico. Em Aberto, Brasília. Disponível em: $<$ www.inep.gov.br $>$. Acesso em: 01/07/2019.

ARNOLD, J. R. T. Administração de materiais. $3^{a}$ ed. São Paulo: GEN, 2011.

BERTAGLiA, P. R. Logística e gerenciamento da cadeia de abastecimento. $2^{\mathrm{a}}$ ed., São Paulo: Saraiva, 2009.

CARRETONI, E. Administração de Materiais: uma abordagem estrutural. Campinas: Alínea, 2000.

CARVALHO, J. M. C. Logística. 3ª ed. Lisboa: Editora Silabo, 2016

CASTIGLiONI, J. A. de Mattos. Logística Operacional. $2^{\circ}$ Ed, São Paulo: Érica. 2010

CHING, H. Y. Gestão de Estoque na Cadeia de Logística Integrada: Supply Chain. $4^{\mathrm{a}}$.Ed, São Paulo: GEN, 2010.

DIAS, M. A. P. Administração de Materiais: Princípios, Conceitos e Gestão. $6^{\text {a }}$ Ed., São Paulo: GEN, 2010.

FNDE, Fundação Nacional Desenvolvimento da Educação Disponível em: $<\underline{\text { http://www.fnde.gov.br/index.php/programas/alimentacao-escolar/alimentacao-escolar- }}$ apresentacao $>$ Acesso em 25/09/2019

GASNIER, D. G. A dinâmica dos estoques: guia prático para planejamento, gestão de materiais e logística. São Paulo: IMAM, 2007. 
MAEHLER, A. E; CERETTA, P. S; CASSANEGO JÚNIOR, P. Aplicação do Método de Criticidade de Materiais em Estoques Hospitalares. XXIV ENEGEP. Florianópolis, 2004. Disponível em: <http://www.abepro.org.br/biblioteca/ENEGEP2004 Enegep0112 0675.pdf> Acesso em 25/09/2019

MARTINS, P.G.; ALT, P.R.C. Administração de Materiais e Recursos Patrimoniais. $3^{\text {a }}$ Ed. São Paulo, Editora Saraiva, 2011.

OLIVEIRA, D. A. G.: Avaliação química, nutricional e sensorial de uma mistura à base de farinhas de arroz, banana e mandioca enriquecida com outras fontes proteicas. 1997. 79 F. Dissertação (Mestrado Em Ciência E Tecnologia De Alimentos). Escola Superior De Agricultura Luiz De Queiroz, Piracicaba, 1997.

PAOLESCHI, B. Almoxarifado e Gestão de Estoques: Do Recebimento, Guarda e Expedição à Distribuição do Estoque. $2^{\mathrm{a}}$ ed. São Paulo: Erica, 2018.

PNAE, Programa Nacional de Merenda Escolar: Merenda Escolar $<$ http://www.portaldatransparencia.gov.br/aprendaMais/documentos/cursoPNAE.pdf Acesso em 21/06/2019.

POZO, H. Administração De Recursos Materiais E Patrimoniais: Uma Abordagem Logística. 7ª ed., São Paulo, Ed. GEN, 2016.

SÃO PAULO. Sistema de Alimentação Escolar do Estado de São Paulo. Disponível em: $<$ https://midiasstoragesec.blob.core.windows.net/001/2017/05/manual-orientao-bsica-saesp-iinova-baixa-diria-03-05-17-1.pdf. $>$ Acesso em: 17/08/219.

VIANA, J. J. Administração de materiais: um enfoque prático. São Paulo: GEN, 2012.

Revista ENIAC Pesquisa, Guarulhos (SP), V.9, n.1, fev.- jul. 2020. 